\title{
Model of personnel activities in emergencies during the operation of an electric power facility
}

\author{
$D Y$ Alekin $^{1, *}, O V$ Soloveva $^{2}, E E$ Kostyleva ${ }^{2}$ and $N G$ Yagovkin ${ }^{1}$ \\ ${ }^{1}$ Samara State Technical University, Samara, St.Molodogvardeyskaya, 244, Russia \\ ${ }^{2}$ Kazan State Energy University, Kazan, St. Krasnoselskaya, 51, Russia
}

\begin{abstract}
In this paper, a model of personnel activities in emergencies during the operation of an electric power facility is proposed. The factors that characterize the inerrancy of the activities of operational personnel and their relationships that determine the effectiveness of actions are identified. The efficiency of various strategies of human behavior is a function of properties of the situation, technical condition, as well as characteristics of equipment and professional attributes of the person.
\end{abstract}

\section{Introduction}

The content of operational activities is close to the ideas of its constituents [1-5]: motive, purpose, processing of current information; diagnosing, planning, building a conceptual model, making a decision, acting, checking the results and correcting the action. Such a sequence makes it possible to consider the designated structure of operational activities not to be random.

However, a clear plan of action and discipline of execution is in itself a valuable quality, but this leads to a paradoxical situation: the more operational personnel "accumulated" ready-made action algorithms used to recognize a case, the less he is able to analyze a nonstandard situation and develop an action plan for short time limited by circumstances [6-8].

Operational personnel have several alternative ways of doing things of different effectiveness, with which they can try to reach the goal. However, it is necessary to evaluate several possible results and methods of actions of varying effectiveness, as well as the personal attitude of the human operator to them. The situation of choice imposes more diverse and complex requirements on staff than just the discipline of execution [9-10].

\section{Method}

The essence of behavior of operational personnel is that it continues to pursue the goal of efficiency in the process of fulfilling a task, changing its behavior when the external conditions change. Four components determine its status:

- The person making a choice;

- Situation (environment) of the decision $S$;

- Available modes of action $C_{i}$;

- Results possible in this situation $O_{j}$.

The parameters of the state of the production system are as follows:
$P_{i}$ is the probability that a person chooses a particular method of action $C_{i}$ in a given situation $S$ (plans of action are a list of possible objective control actions in a given situation, united by a particular strategy of behavior of operational personnel);

$E_{i j}$ is the effectiveness of the mode of operation (the probability that a specific way of action $C_{i}$ will lead to an inevitable desired result $O_{j}$ in a particular situation S);

$V_{j}$ is the value of consequence $O_{j}$ for the implementation of specific actions (depends both on the objective value of the result $O_{j}$ and on the motives formed by external requirements and the incentives of the staff).

The operator can build his model of the situation of choice by the factors of the complexity of the $K_{i p}$, as well as the components and parameters of the system.

Expressions connecting the parameters and components of the model to obtain the most effective result are:

$$
\begin{gathered}
P_{i}=f\left[\left\{K_{i p}\right\},\{C i\},\left\{O_{j}\right\}, v_{j}, S\right], \\
E_{i j}=g\left[\left\{K_{i p}\right\},\{C i\},\left\{O_{j}\right\}, S\right], \\
V_{j}=h\left[\left\{C_{i}\right\},\left\{O_{j}\right\}, v_{j}, S\right],
\end{gathered}
$$

where $v_{j}$ is the value of the results, $f, g, h$ are functions.

The model of situational choice is not the totality of all knowledge about an object, but a highly specialized tool for solving a specific operational task, therefore it does not fully reflect the human condition, system, and situation [11].

The functions $f, g, h$ are essential characteristics of the individuality of the operator. Differences in identity should determine differences in the results of actions, i.e., if one person does not solve one operational task, then the difference between them is reflected in the values of $P_{i}, E_{i j}$ and $V_{j}$.

* Corresponding author: Alekina-samgtu@mail.ru 


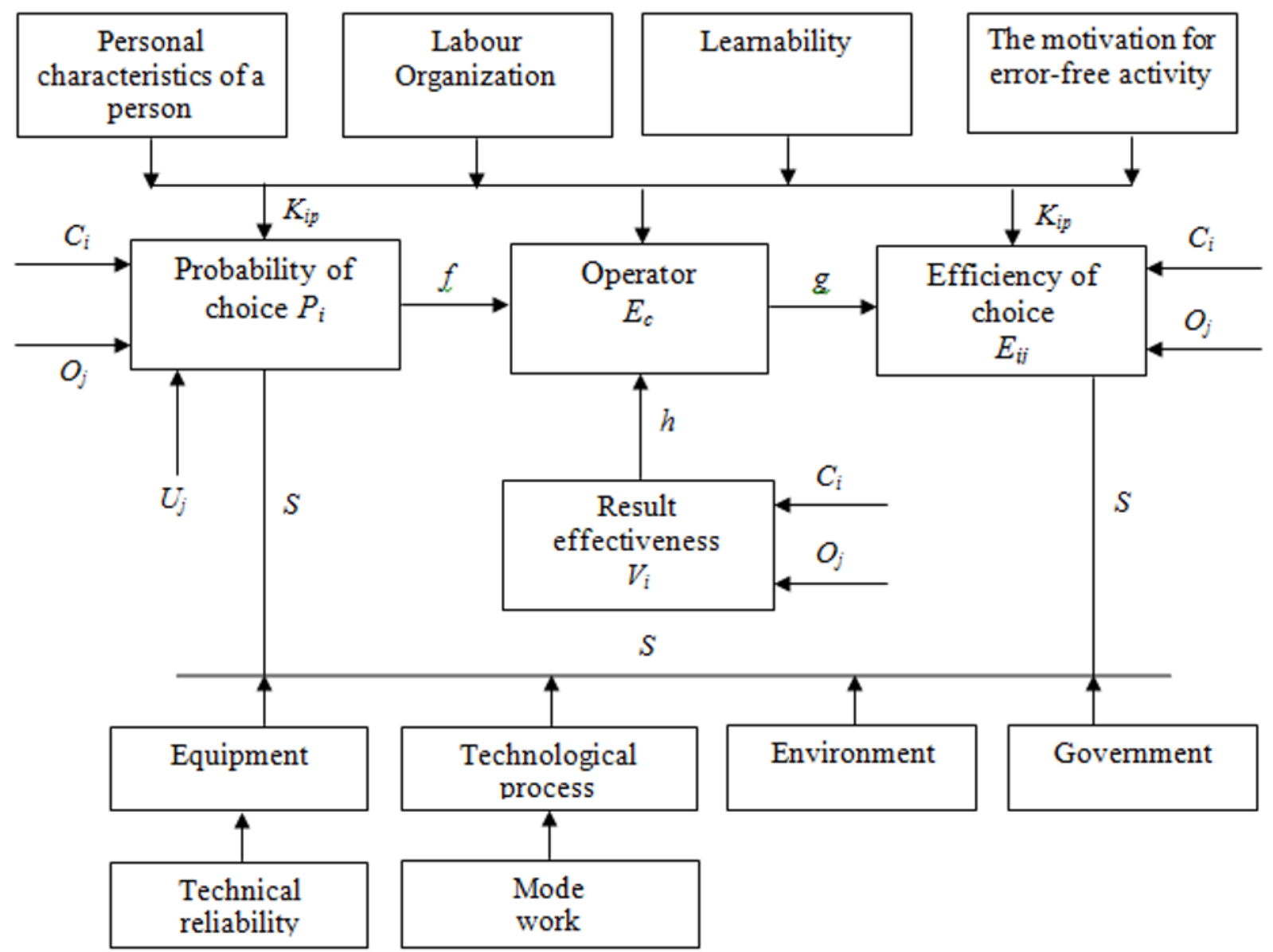

Fig. 1. Diagram of the backbone factors of relationships that characterize the accuracy of the activities of operating personnel.

Quantitative expressions of parameters of the state of the electro-control are determined based on observations of human actions in the process of solving operational tasks [12].

The interaction of subsystems and their causal relationships are manifested under the influence of some factors, one of which is the human-operator (Figure 1).

When carrying out activities, the diagram is expressed in a rigidly deterministic relationship:

Events $\rightarrow$ Consequences $\rightarrow$ Compensating actions.

The quantitative technical reliability of the device is expressed by the probability $\mathrm{P}(\tau)$ of its trouble-free operation in these operating conditions for a specified time. Mathematically, this indicator can be defined as the probability of an event at which the uptime $T$ of a device, which is a random variable, will be greater than a certain specified time

$$
P(\tau)=P(T>\tau)
$$

The main component of a power industry object is the operational personnel, which ensures its efficiency, including that in an unusual situation.

If as a result of a change in the operating mode or technical failure, a situation $\mathrm{S}$ arises, then it is necessary to influence the actuators in a certain way to achieve the result $O_{j}$. The reliability of the operational personnel will be determined by the probability of obtaining a given result $O_{j}$ in a specific situation in a given time $T$ in a particular case $S$. We denote by $P\left(O_{j}\right)$ the probability of achieving the result $O_{j}$ in situation $S$. For a person, $P\left(O_{j}\right)$ is a function of the parameters $P_{i}, E_{i j}, V_{j}$, which are amenable to change during the formation of skills, and the factors $C_{i}, O_{j}$ and $S$, which depend on the situation, instructions, condition and characteristics of the equipment.

The reliability criterion of the energy facility can be presented analytically. However, such a definition is not so much constructive as pragmatic, since it does not indicate how to find functional relationships between the input parameters [12-15].

The reliability of a person is estimated by the probability of achieving a given result by the principle "all - or nothing". Reliability condition is:

$$
P\left(O_{j}\right)=\sum_{i} P_{i} E_{i j}
$$

The probability and effectiveness of choice depend on:

- Properties of the situation (possible action methods $C_{i}$, and potential results $O_{j}$ );

- Technical condition and equipment characteristics;

- Personal characteristics of the person (properties of the nervous system, focus, emotional and volitional 
qualities, responsibility, etc.), which determine the value of the $V_{j}$-th or another result.

The following factors that are more distant and stable with current situations can influence $P_{i}$ and $E_{i j}$ :

- Compliance of the design decisions with the actual operating conditions of $\mathrm{K}_{0}$;

- Quality of the adopted design decisions $\mathrm{K}_{\mathrm{p}}$;

- Quality of the overhaul $\mathrm{K}_{\mathrm{ov}}$;

- Efficiency of maintenance service $\mathrm{K}_{\mathrm{e}}$;

- Occurrence of $\mathrm{m}$ environmental conditions S, i.e., $\mathrm{S}_{\mathrm{m}}$.

An event consisting in achieving a given result can occur with various factors $\mathrm{K}$, which occur respectively with the probabilities $\mathrm{P}\left(\mathrm{C}_{\mathrm{i}}\right), \mathrm{P}\left(\mathrm{O}_{\mathrm{j}}\right), \mathrm{P}\left(\mathrm{V}_{\mathrm{j}}\right), \mathrm{P}\left(\mathrm{S}_{\mathrm{m}}\right), \mathrm{P}$ $\left(\mathrm{K}_{\mathrm{p}}\right), \mathrm{P}\left(\mathrm{K}_{\mathrm{o}}\right), \mathrm{P}\left(\mathrm{K}_{\mathrm{ov}}\right), \mathrm{P}\left(\mathrm{K}_{\mathrm{e}}\right)$.

The following expression determines the effectiveness of a given result.

$$
E=\sum_{\alpha=1}^{n} P\left(K_{\alpha}\right) P\left(O_{j}\right) / K_{\alpha}
$$

where $P\left(K_{\alpha}\right), \quad P\left(O_{j} \quad / K_{\alpha}\right)$ are the probabilities of occurrence of $K_{\alpha}$ factor influencing the operation of an electric power facility and the reliable work of a person under the conditions of $K_{\alpha}$ factor.

\section{Results}

The efficiency of various strategies of human behavior in a particular situation does not depend on him; they are given and are functions of the specific conditions of the problem.

Analysis of activities of personnel in the operation of electric power facilities makes it possible to formulate the main tasks of the theory of action:

- Study of the influence of constructive, communicative and regular properties of electric power facilities on the method and structure of their operation;

- Review of the impact of valuable commutative and periodic properties of objects on the way and construction of their service;

- Study the effectiveness of the objects features;

- Optimization of operating modes and forms of work organization of operating personnel;

-Development of principles, methods, and means of monitoring the functional state of staff during work;

- Analysis of group activities and interaction of operating personnel of different profiles and levels;

- System analysis methods of operation;

- Organization of the objects use in case of damage and accidents;

- Intensification of the processes of maintenance of objects.

\section{Conclusions}

In view of the foregoing, when assessing a person's preparedness for work in an emergency, it is necessary to take into account the timeliness of a person's identification of the causes that led to the emergence of an emergency and the timeliness and correctness of a decision in order to form a conceptual model of activity for him. This model includes an assessment of the situation and the development of an action plan and the accuracy of forecasting the development of events and the effectiveness of actions aimed at localizing the emergency.

The developed model of information processing and decision-making strategies in the automated control system of a complex electric power facility is the basis for the development of operational safety management systems and operational switching at power plants. The decision-making strategy determines the professional competencies necessary for the correct response in an emergency and the optimization of the operations of operational personnel. The constructed model of operations of operational personnel makes it possible to predict technological violations, accidents, and accidents, which is necessary when developing qualification requirements for the suitability of personnel for activities at electric power facilities

\section{References}

1. M. Vadari, Electric System Operations: Evolving to the Modern Grid, 251 (2013)

2. 1970-2004, OSHA's regulations, 29 CFR 1910 Occupational Safety and Health Administration, subpart S Electrical

3. 2015, NFPA 70E, Standard for Electrical Safety in the Workplace

4. E. Battistoni, A. Bonacelli, A. Colladon, M. Schiraldi, Analysis of the Effect of Operations Management Practices on Performance, 1-11 (2013)

5. N.N. Kostechko, A.A. Kostyukov, L.S. Kulikov, N.G. Yagovkin, Methodological aspects of building automated information-processing systems Samara RAS SSC, 60 (2004)

6. G.N. Yagovkin, S.A. Panyukova, M.A. Krivova, Model of the formation of a dangerous situation in the production system, News of Samara scientific. Center of Sciences, 1(9)(33), 2281-2284 (2010)

7. P.G. Belov, Theoretical foundations of system engineering security, 424 (1996)

8. E.V. Alekina, G.N. Yagovkin, Diagnostic operator activity in the operation of technical systems, Proceedings of the International scientific-practical conference "Ashirov readings", 2, 286-291 (2016)

9. E.V. Alekina, D.A. Melnikova, G.N. Yagovkin, Theoretical foundations of the formation of an integrated production safety management system, Monograph Go Tech, 281 (2018)

10. V.D. Nebylytsin, The reliability of the operator in a complex control system, 358-367 (1964)

11. N.I. Arkhipova, Research of management systems, 240 (2002)

12. V.I. Batishchev, N.G. Yagovkin, Methodology of decision support in the management of integrative large-scale production systems, 142 (2008) 
13. E. Mushikh, P. Muller, Methods of making technical decisions, 208 (1990)

14. A.A. Bashlykov, Designing decision-making systems in the energy sector, 318 (1986)

15. A.L. Trakhtengerts, Computer decision support, 247 (1998) 